Article

\title{
Stress-Induced Magnetic Anisotropy Enabling Engineering of Magnetic Softness and GMI Effect of Amorphous Microwires
}

\author{
Paula Corte-León ${ }^{1,2}$, Ahmed Talaat ${ }^{1,2}{ }^{1}$, Valentina Zhukova ${ }^{1,2}\left(\mathbb{D}\right.$, Mihail Ipatov ${ }^{1,2}$, \\ Juan María Blanco ${ }^{2}$, Julián Gonzalez ${ }^{1}$ and Arcady Zhukov ${ }^{1,2,3, *(D)}$ \\ 1 Department Physics of Materials, Chemistry Faculty, University of Basque Country, UPV/EHU, \\ 20018 San Sebastian, Spain; paula.corte@ehu.eus (P.C.-L.); ahmedtalaatfarag@gmail.com (A.T.); \\ valentina.zhukova@ehu.es (V.Z.); mihail.ipatov@ehu.es (M.I.); julianmaria.gonzalez@ehu.es (J.G.) \\ 2 Department of Applied Physics, EIG, University of Basque Country, UPV/EHU, 20018 San Sebastián, Spain; \\ juanmaria.blanco@ehu.es \\ 3 IKERBASQUE, Basque Foundation for Science, 48011 Bilbao, Spain \\ * Correspondence: arkadi.joukov@ehu.es; Tel.: +34-943-018611
}

Received: 24 December 2019; Accepted: 30 January 2020; Published: 3 February 2020

\begin{abstract}
Stress-annealing enabled a considerable improvement in the GMI effect in both Fe- and Co-rich glass-coated microwires. Additionally, a remarkable magnetic softening can be achieved in stress-annealed Fe-rich microwires. Observed stress-annealing induced magnetic anisotropy is affected by annealing conditions (temperatures and stresses applied during annealing). The highest GMI ratio up to $310 \%$ was obtained in stress-annealed Co-rich microwires, although they presented rectangular hysteresis loops. A remarkable magnetic softness and improved GMI ratio over a wide frequency range were obtained in stress-annealed Fe-rich microwires. Irregular magnetic field dependence observed for some stress-annealing conditions is attributed to the contribution of both the inner axially magnetized core and outer shell, with transverse magnetic anisotropy.
\end{abstract}

Keywords: GMI effect; magnetic microwires; magnetic softness; annealing; magnetic anisotropy

\section{Introduction}

Magnetic wires exhibit versatile physical properties such as the Giant Magnetoimpedance (GMI) effect [1-3] and fast propagation of a single domain wall (DW) [4,5]. Although these properties are not solely restricted to amorphous magnetic wires $[3,6]$, the former family presents several advantages, like better mechanical properties $[7,8]$ as well as a fast and inexpensive preparation method involving rapid solidification from the melt [9-11]. Consequently, the highest GMI effect and the fastest DW propagation were reported in either Co-rich or Fe-rich amorphous microwires, respectively [4,5,12-14]. From the viewpoint of applications, excellent magnetic field sensitivity of the GMI effect reported for soft magnetic wires (up to $10 \% / \mathrm{A} / \mathrm{m}$ ) is certainly of great technological interest [12-15]. In this context, a number of magnetic sensors and magnetometers enabling the detection of low magnetic field or external parameters (e.g., stresses, temperature) based on GMI effect were designed and reported [16-28].

On the other hand, thin magnetic wire inclusions can be relevant for some other recent technological developments, like metamaterials [29,30]. In particular, specific magnetic structures containing arrays of amorphous magnetic wires allow us to achieve high sensitivity of the surface impedance to external stimuli and hence are useful for development of tunable metamaterials and metacomposites [30-32].

As compared to conventional metamaterials [29], the special feature of tunable metamaterials and metacomposites with soft magnetic wire inclusions is that they can demonstrate strong tunability 
with respect to the varying of external stimuli, such as magnetic field, mechanical load and heat [30-32]. Consequently, metamaterials incorporating arrays of magnetic wires in fiber-reinforced polymer composites are potentially suitable for engineering of electromagnetic functionalities and stress/temperature monitoring.

Industrial applications based on the GMI effect demand a size reduction of the magnetic element $[16,17]$. Therefore, the development of thin wires exhibiting GMI effect has become a topic of intensive research [4,5,11-15]. Among different preparation techniques of magnetic wires, the so-called Taylor-Ulitovsky method allows for the thinnest wires' fabrication and reduced dimensions [11-16,31-33]. In order to observe the GMI effect in thin wires, the skin depth should be lower than the radius of the wire. As such, a decrease in diameter should be associated with an increase in the frequency range for observation of the GMI effect $[34,35]$. Besides these technical features, the overall cost should be also considered for applications (e.g., smart composites with wire inclusions) where substantial amounts of wires are required.

Excellent soft magnetic properties with enhanced GMI effects are usually reported for as-prepared Co-rich [11-15] and nanocrystalline Fe-rich magnetic microwires [36,37]. The latter are often accompanied with an inherent brittleness of samples over the course of the nanocrystallization process, and therefore alternative stress-annealing approaches have been proposed, to enhance the GMI effect retaining the amorphous structure [38,39]. Stress-annealing can be performed in a temperature range well below the crystallization onset. In addition, the degree of stress-induced anisotropy can be selectively tuned through optimal annealing temperature, time and/or different values of applied stresses. Thus, this contribution aims at providing comparative studies on the effect of stress-induced anisotropy on magnetic softness and GMI effect in Fe-and Co-rich magnetic microwires.

\section{Materials and Methods}

We studied magnetic properties and GMI effect in $\mathrm{Fe}_{75} \mathrm{~B}_{9} \mathrm{Si}_{12} \mathrm{C}_{4}$ (metallic nucleus diameter, $\mathrm{d}$ $=15.2 \mu \mathrm{m}$, total diameter, $\mathrm{D}=17.2 \mu \mathrm{m})$ and $\mathrm{Co}_{69.2} \mathrm{Fe}_{4.1} \mathrm{~B}_{11.8} \mathrm{Si}_{13.8} \mathrm{C}_{1.1}(\mathrm{~d}=25.6 \mu \mathrm{m} ; \mathrm{D}=30.2 \mu \mathrm{m})$ microwires prepared by using the Taylor-Ulitovsky technique described elsewhere [11,12]. Fe-rich composition presents positive and high magnetostriction coefficient, $\lambda \mathrm{s}$ (about $40 \times 10^{-6}$ ) $[22,23]$, while Co-rich wires have low negative and vanishing magnetostriction values (about $-3 \times 10^{-7}$ ) $[40,41]$.

We measured the impedance, $\mathrm{Z}$, and its magnetic field dependence over a wide range of frequencies (10-900 MHz), using a vector network analyzer. As-prepared and stress-annealed samples were placed in a micro-strip sample holder, and impedance was obtained from the reflection coefficient S11, as described elsewhere [42]. From Z-values obtained for different magnetic fields, H, we evaluated the magnetic field dependences of the GMI ratio, $\Delta \mathrm{Z} / \mathrm{Z}$, which is defined as follows:

$$
\Delta \mathrm{Z} / \mathrm{Z}=\left[\mathrm{Z}(\mathrm{H})-\mathrm{Z}\left(\mathrm{H}_{\max }\right)\right] / \mathrm{Z}\left(\mathrm{H}_{\max }\right),
$$

where $\mathrm{H}_{\max }$ is the maximum applied DC magnetic field. In order to compare the frequency dependence on the GMI effect, we plotted frequency, $f$, dependence of a maximum GMI ratio, $\Delta Z / Z_{m}$, defined as a maximum $\Delta \mathrm{Z} / \mathrm{Z}$ obtained at a given frequency.

Hysteresis loops of as-prepared and stress-annealed samples were measured by the flux metric methods described elsewhere [12,38]. For a better comparison of samples annealed under different conditions, we represent the hysteresis loops as the normalized magnetization, $M / M_{0}$ versus the applied magnetic field, $\mathrm{H}$, where $\mathrm{Ms}$ is the magnetic moment at the maximum amplitude of magnetic fields, $\mathrm{H}_{\max }$.

Annealing treatments were conducted in a conventional furnace, with and without stress, at temperatures, $\mathrm{T}_{\mathrm{ann}}$, below the crystallization typically observed above $450-500^{\circ} \mathrm{C}$. The stress-annealing process was performed under the attachment of different mechanical loads, to one end of the microwire. Different values of mechanical loads allowed us to apply tensile stresses during the annealing, $\sigma_{a}$, up 
to $900 \mathrm{MPa}$. The stress value during the annealing, $\sigma_{\mathrm{a}}$, within the metallic nucleus and glass shell was evaluated, as described elsewhere [38,39].

\section{Results and Discussion}

\subsection{Tuning of Fe-Rich Microwires by Stress-Annealing}

As expected for Fe-rich microwires with high and positive $\lambda \mathrm{s}$ values, the as-prepared sample presents rectangular hysteresis loop with coercivity, Hc, of about $55 \mathrm{~A} / \mathrm{m}$ (see Figure 1a). Annealing without stress did not considerably affect the hysteresis loop shape. Upon annealing at $\mathrm{T}_{\mathrm{ann}}=350{ }^{\circ} \mathrm{C}$, the hysteresis loop of as-prepared microwires maintained its rectangular shape; however, the coercivity, $\mathrm{Hc}$, slightly decreased up to $50 \mathrm{~A} / \mathrm{m}$, as shown in Figure $1 \mathrm{~b}$. The hysteresis loop of the sample annealed under stress (Figure 1c) was changed completely: the stress-annealed sample presented a linear hysteresis loop with low values of coercivity (about $17 \mathrm{~A} / \mathrm{m}$ ). Both the stress applied during annealing (Figure 2) and the annealing temperatures (Figure 3) affected the character of hysteresis loops, showing a higher magnetic anisotropy field, $\mathrm{H}_{\mathrm{k}}$, by raising $\sigma_{\mathrm{a}}$ or $\mathrm{T}_{\mathrm{ann}}$.

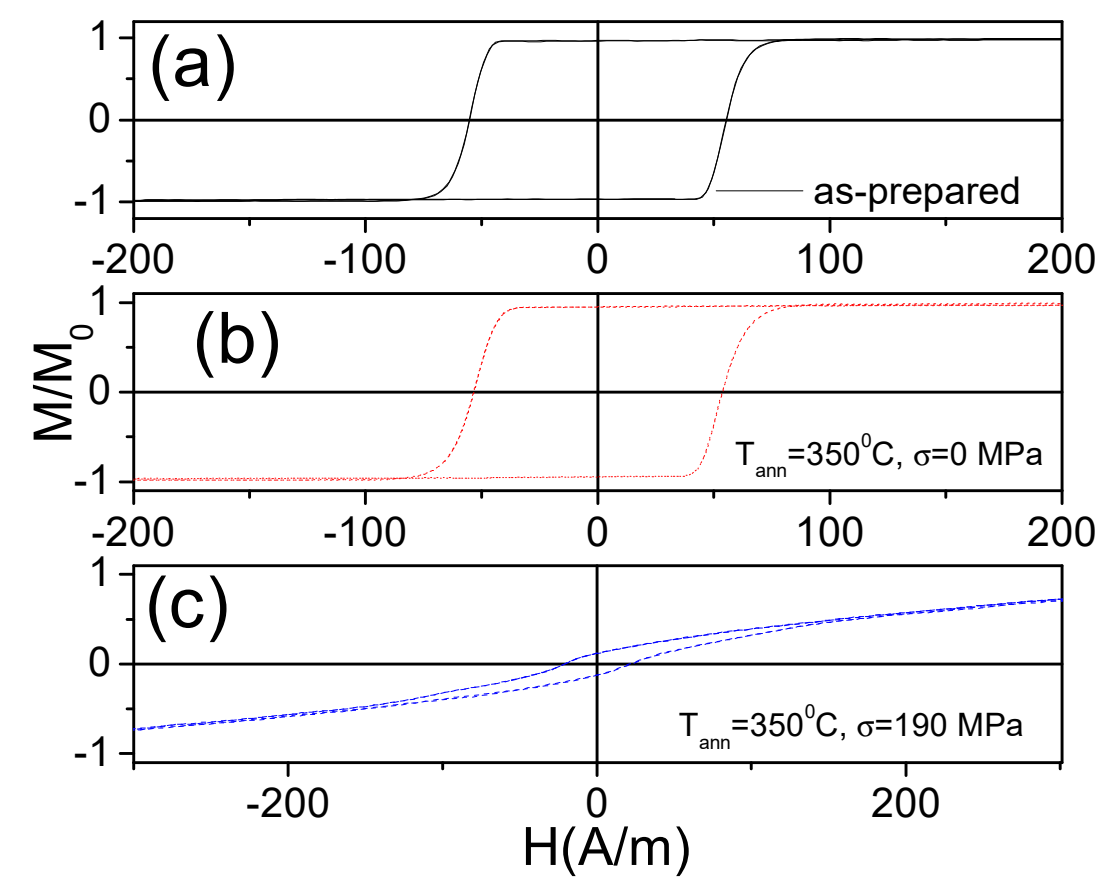

Figure 1. Hysteresis loops of as-prepared (a); annealed at $\mathrm{T}_{\mathrm{ann}}=350{ }^{\circ} \mathrm{C}$ for $\sigma_{\mathrm{a}}=0 \mathrm{MPa}(\mathbf{b})$, and at $\mathrm{T}_{\mathrm{ann}}$ $=350{ }^{\circ} \mathrm{C}$ for $\sigma_{\mathrm{a}}=190 \mathrm{MPa}(\mathbf{c}) \mathrm{Fe}_{75} \mathrm{~B}_{9} \mathrm{Si}_{12} \mathrm{C}_{4}$ microwires. 


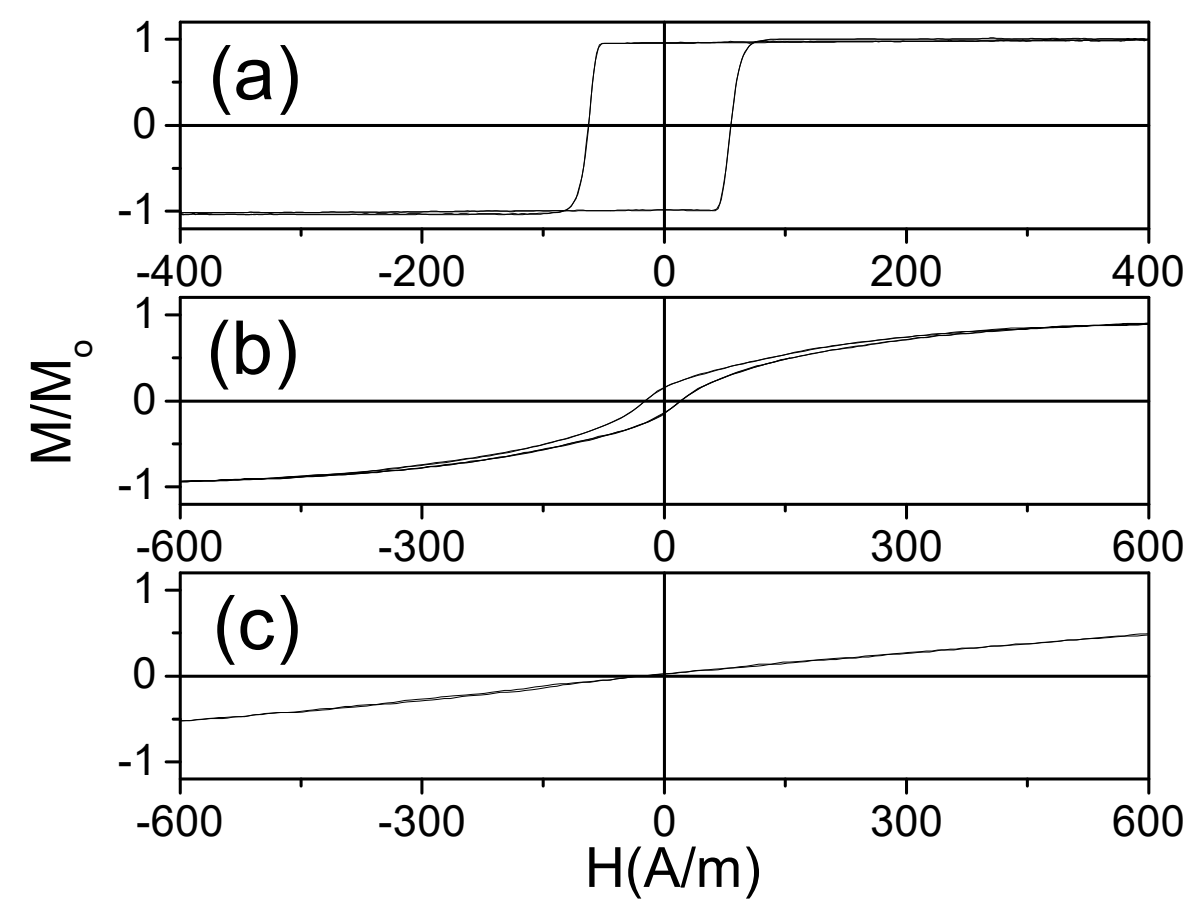

Figure 2. Hysteresis loops of as-prepared (a); stress-annealed at $\mathrm{T}_{\mathrm{ann}}=300{ }^{\circ} \mathrm{C}$ for $\sigma_{\mathrm{a}}=450 \mathrm{MPa}(\mathbf{b})$, and for $\sigma_{\mathrm{a}}=900 \mathrm{MPa}(\mathbf{c}) \mathrm{Fe}_{75} \mathrm{~B}_{9} \mathrm{Si}_{12} \mathrm{C}_{4}$ microwires.

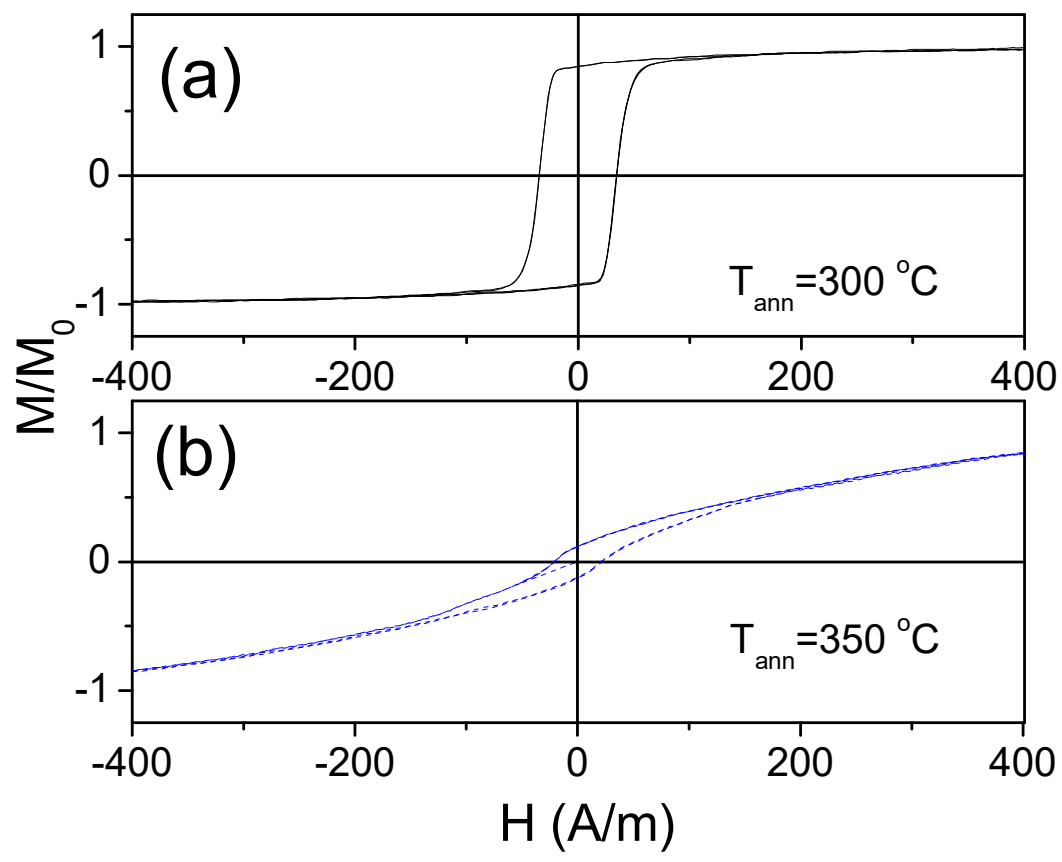

Figure 3. Hysteresis loops of stress-annealed at $\mathrm{T}_{\mathrm{ann}}=300^{\circ} \mathrm{C}(\mathbf{a})$ and $\mathrm{T}_{\mathrm{ann}}=350{ }^{\circ} \mathrm{C}$ for $\sigma_{\mathrm{a}}=190 \mathrm{MPa}$ (b) $\mathrm{Fe}_{75} \mathrm{~B}_{9} \mathrm{Si}_{12} \mathrm{C}_{4}$ microwires.

Similar to a previously reported GMI effect for Fe-rich microwires, the GMI effect of the as-prepared sample is quite low (Figure 4a). The GMI ratio, $\Delta \mathrm{Z} / \mathrm{Z}$ presented a single peak dependence, with decay from $\mathrm{H}=0$, as predicted for wires with axial magnetic anisotropy [42-45]. As can be seen in Figure 4b,c, stress-annealing allowed for considerable improvement of the GMI ratio. Additionally, the character of the $\Delta \mathrm{Z} / \mathrm{Z}(\mathrm{H})$ dependencies became different: starting from $f \geq 100 \mathrm{MHz}$ double peak $\Delta \mathrm{Z} / \mathrm{Z}(\mathrm{H})$, dependencies were observed for stress-annealed samples (Figure $4 b, c)$. Rather unusual character of $\Delta \mathrm{Z} / \mathrm{Z}(\mathrm{H})$ dependencies was observed for the sample annealed $\sigma_{\mathrm{a}}=900 \mathrm{MPa}\left(\mathrm{T}_{\mathrm{ann}}=300{ }^{\circ} \mathrm{C}\right)$ : 
at intermediate $f$-values $(f=100 \mathrm{MHz}), \Delta \mathrm{Z} / \mathrm{Z}(\mathrm{H})$ dependence showed an irregular shape, consisting of single and double-peak $\Delta \mathrm{Z} / \mathrm{Z}(\mathrm{H})$ dependencies. Considering the core-shell model $[46,47]$ of the domain structure of magnetic wires (proved experimentally [48]), the radius of the inner axially magnetized core, $R_{c}$, can be evaluated based on its relationship with the squareness ratio, $M_{r} / M_{o}$ :

$$
\mathrm{R}_{\mathrm{c}}=\mathrm{R}\left(\mathrm{M}_{\mathrm{r}} / \mathrm{M}_{\mathrm{o}}\right)^{1 / 2}
$$

where $\mathrm{R}$ is the metallic nucleus radius. From observed hysteresis loops in Figures 2 and 3 , the reduction of $\mathrm{M}_{\mathrm{r}} / \mathrm{M}_{\mathrm{o}}$ upon stress-annealing can be evidenced.
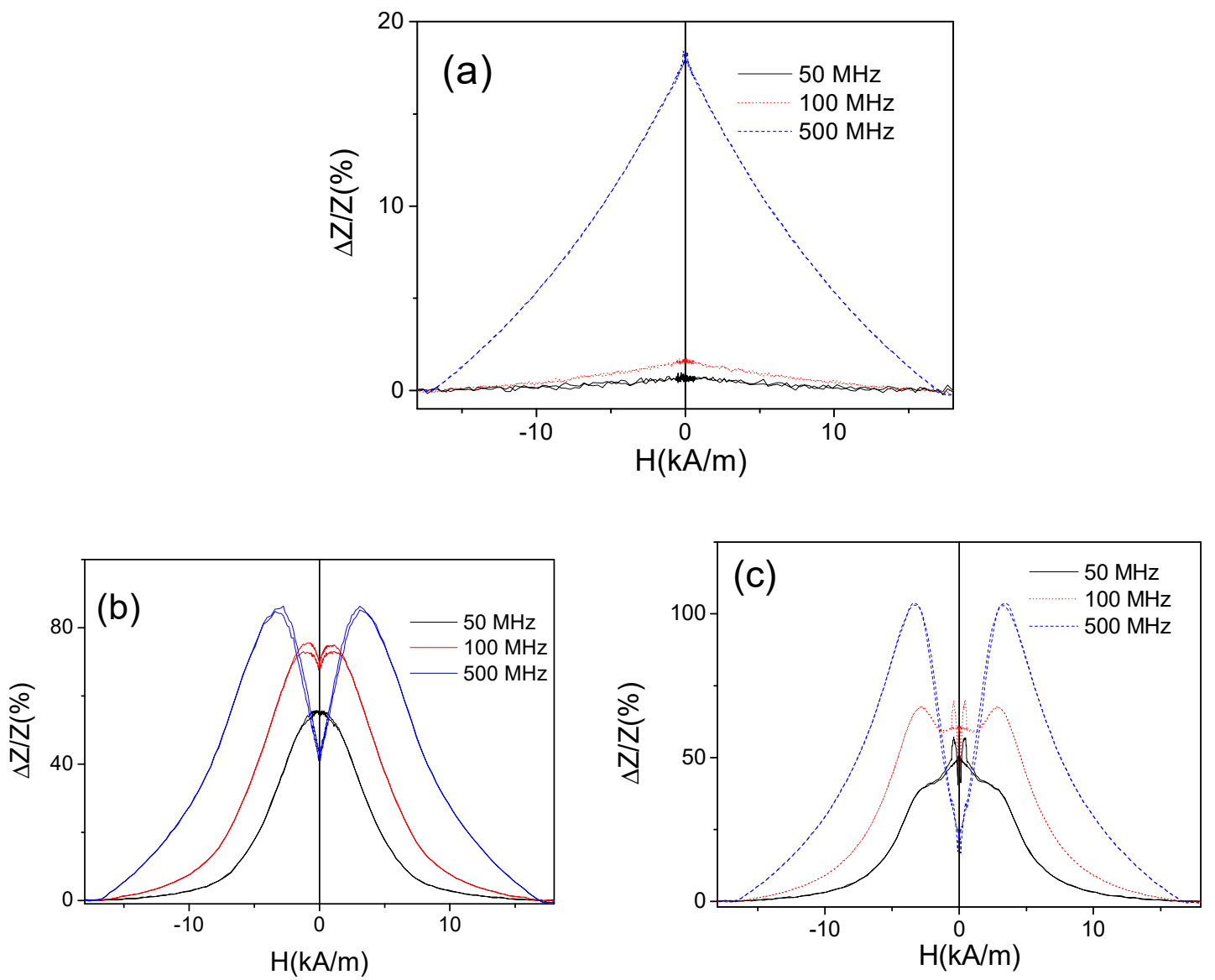

Figure 4. $\Delta \mathrm{Z} / \mathrm{Z}(\mathrm{H})$ dependencies of as-prepared (a); stress-annealed at $\mathrm{T}_{\mathrm{ann}}=300{ }^{\circ} \mathrm{C}$ for $\sigma_{\mathrm{a}}=390 \mathrm{MPa}$ (b) and for $\sigma_{\mathrm{a}}=900 \mathrm{MPa}(\mathrm{c}) \mathrm{Fe}_{75} \mathrm{~B}_{9} \mathrm{Si}_{12} \mathrm{C}_{4}$ microwires.

On the other hand, the skin depth of a cylindrical magnetic conductor, $\delta$, is affected by the circumferential magnetic permeability, $\mu_{\phi}$, and by the frequency, $f$, as follows:

$$
\delta=\left(\pi \sigma \mu_{\varphi} f\right)^{-1 / 2}
$$

where $\sigma$ is the electrical conductivity. Considering the aforementioned, one can assume the contribution of the inner axially magnetized core for low frequencies and an increase in the contribution of the outer shell with increasing frequency. From frequency dependence of maximum GMI ratio, $\Delta \mathrm{Z} / \mathrm{Z}_{\mathrm{m}}$, evaluated for the as-prepared and stress-annealed samples (Figure 5), we can deduce that stress-annealing allowed the improvement of $\Delta \mathrm{Z} / \mathrm{Z}_{\mathrm{m}}$ for a wide frequency range. 


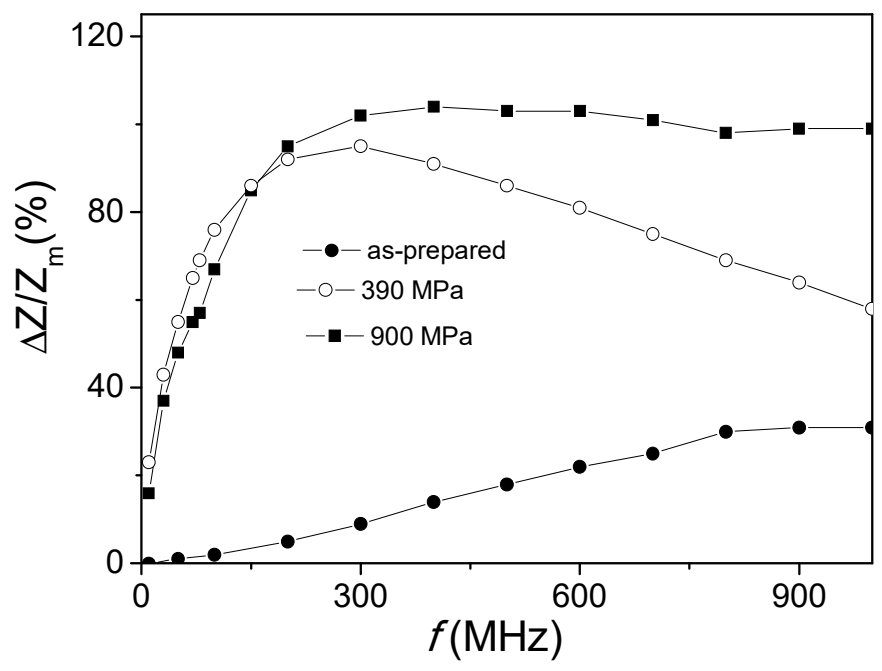

Figure 5. $\Delta \mathrm{Z} / \mathrm{Z}_{\mathrm{m}}(\mathrm{f})$ dependencies of $\mathrm{Fe}_{75} \mathrm{~B}_{9} \mathrm{Si}_{12} \mathrm{C}_{4}$ as-prepared and stress-annealed microwires.

\subsection{Effects of Stress-Annealing on Magnetic Properties and GMI Effect of Co-Rich Microwires}

In contrast to as-prepared Fe-rich samples, as-prepared Co-rich microwires with low negative magnetostriction values $\left(-3 \times 10^{-7}\right)$ [41] displayed linear and almost unhysteretic hysteresis loops (see Figure 6a). However, as we recently reported elsewhere [43,44], considerable magnetic hardening (coercivity rising by more than one order of magnitude) and transformation of linear hysteresis loop into rectangular is observed even after short-time annealing of Co-rich microwires (Figure 6b). In spite of magnetic hardening, annealed Co-rich samples can show higher GMI effect [44]. Stress-annealing of Co-rich microwires can also prevent magnetic hardening, allowing induction of transverse magnetic anisotropy at high enough annealing temperature and GMI ratio improvement [44]. As can be observed in Figure 6c, stress-annealed $\mathrm{Co}_{69.2} \mathrm{Fe}_{4.1} \mathrm{~B}_{11.8} \mathrm{Si}_{13.8} \mathrm{C}_{1.1}$ microwires showed lower coercivity, $\mathrm{H}_{\mathrm{c}}$.

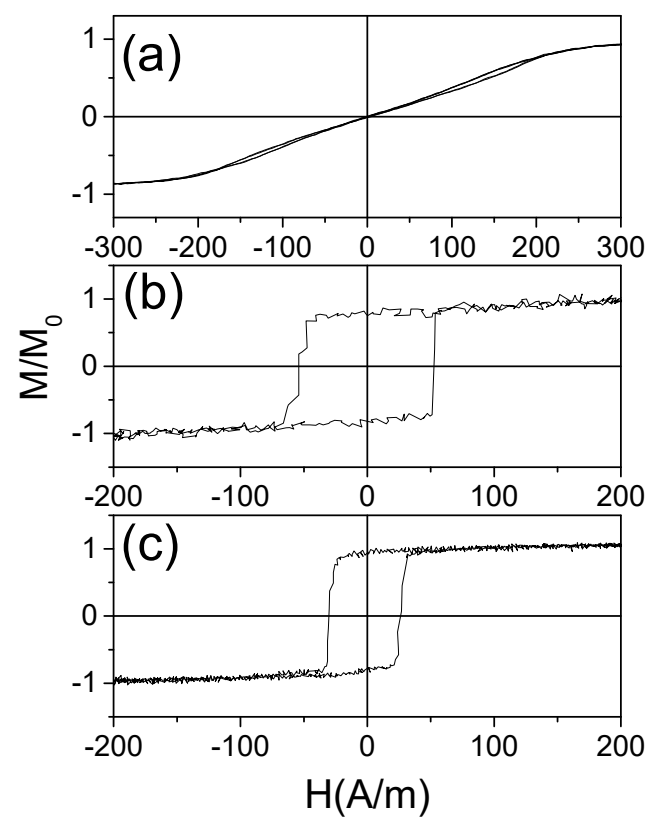

Figure 6. Hysteresis loops of as-prepared (a); annealed at $\mathrm{T}_{\mathrm{ann}}=300{ }^{\circ} \mathrm{C}$ for $\sigma_{\mathrm{a}}=0 \mathrm{MPa}(\mathbf{b})$ and for $\sigma_{\mathrm{a}}=80 \mathrm{MPa}(\mathrm{c}) \mathrm{Co}_{69.2} \mathrm{Fe}_{4.1} \mathrm{~B}_{11.8} \mathrm{Si}_{13.8} \mathrm{C}_{1.1}$ microwires.

As expected, as-prepared the $\mathrm{Co}_{69.2} \mathrm{Fe}_{4.1} \mathrm{~B}_{11.8} \mathrm{Si}_{13.8} \mathrm{C}_{1.1}$ microwire displays an enhanced GMI effect, as shown in Figure $7 \mathrm{a}$ (GMI ratio up to $285 \%$ ), with a double-peak magnetic-field dependence. Such 
$\Delta \mathrm{Z} / \mathrm{Z}(\mathrm{H})$ dependencies are ascribed to a circular magnetic anisotropy with high initial permeability and low coercivity typical for Co-rich microwires with vanishing and negative $\lambda$ s values $[43,44]$. Upon stress-annealing at a fixed $\mathrm{T}_{\mathrm{ann}}=300{ }^{\circ} \mathrm{C} / \sigma_{\mathrm{a}}=80 \mathrm{MPa}$ and different annealing time, a noticeable modification of the $\Delta \mathrm{Z} / \mathrm{Z}(\mathrm{H})$ dependencies, either for $10 \mathrm{~min}$ (Figure $7 \mathrm{~b}$ ) or $30 \mathrm{~min}$ (Figure 7c), has been observed. The maximum GMI ratio, $\Delta \mathrm{Z} / \mathrm{Z}_{\mathrm{m}}$, at $\mathrm{f}=100 \mathrm{MHz}$ decreased from $280 \%$ to $265 \%$ and $250 \%$ for samples stress-annealed at 10 and $30 \mathrm{~min}$, respectively. However, stress-annealed samples present higher $\Delta \mathrm{Z} / \mathrm{Z}_{\mathrm{m}}$ values at high frequency region (Figure $7 \mathrm{~b}-\mathrm{d}$ ). Both stress-annealed samples exhibited maximum on $\Delta \mathrm{Z} / \mathrm{Z}_{\mathrm{m}}$ (f) dependence, at about $200 \mathrm{MHz}$, as can be appreciated from Figure $7 \mathrm{~d}$. For annealing time, $\mathrm{t}_{\mathrm{ann}}=10 \mathrm{~min}, \Delta \mathrm{Z} / \mathrm{Z}_{\mathrm{m}} \approx 310 \%$ was achieved (Figure $7 \mathrm{~b}, \mathrm{~d}$ ). Furthermore, at a lower frequency $(10 \mathrm{MHz})$ the $\Delta \mathrm{Z} / \mathrm{Z}(\mathrm{H})$ dependence showed a single peak character associated with an axial anisotropy induced upon stress-annealing. Observed frequency dependence on $\Delta Z / Z(H)$ can be attributed to the radial distribution of magnetic anisotropies in the core-shell domain structure [46-48]. Consequently, stress-annealing of Co-rich microwires resulted in an increase in the GMI ratio, at frequencies above $400 \mathrm{MHz}$, as can be observed in Figure $7 \mathrm{~d}$.
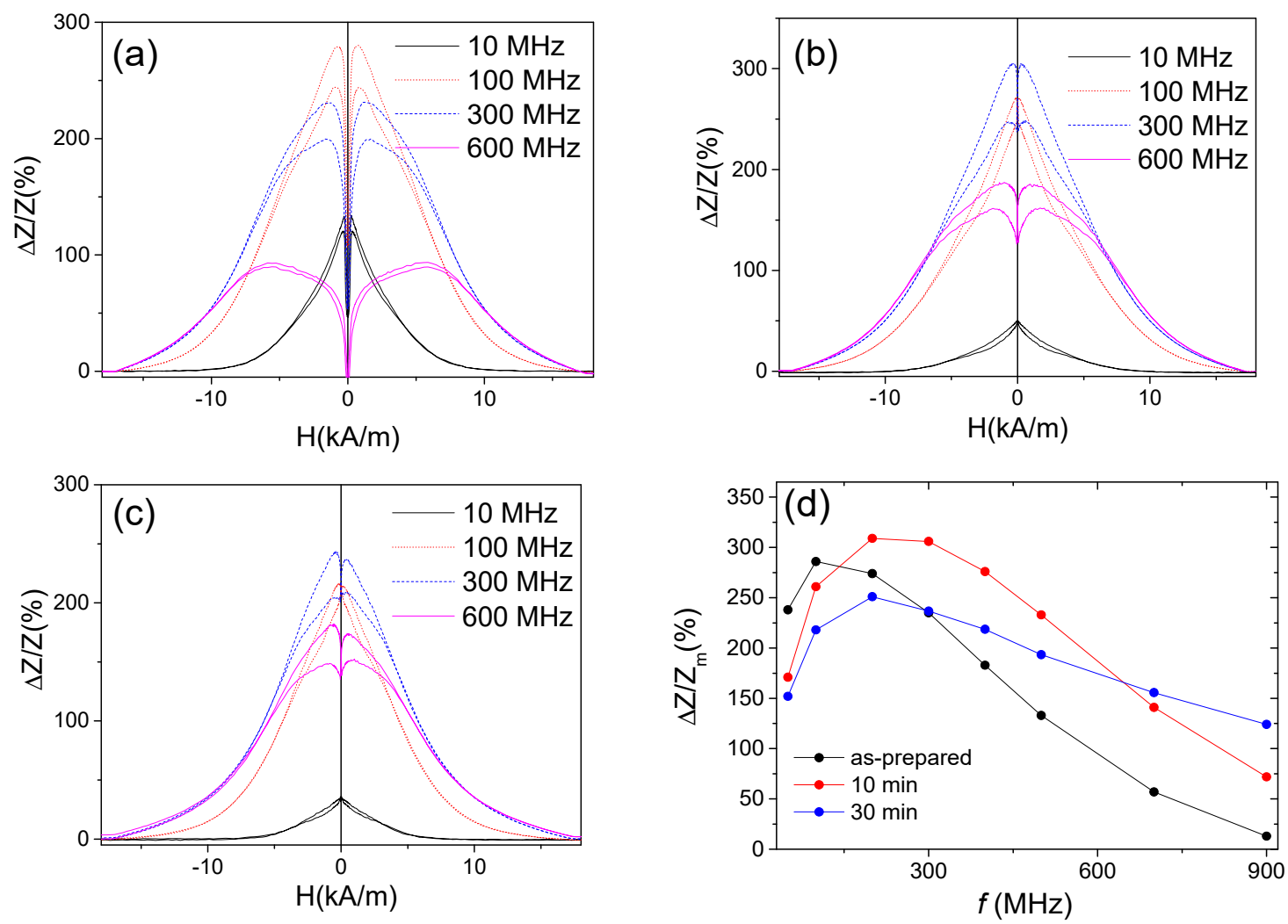

Figure 7. $\Delta \mathrm{Z} / \mathrm{Z}(\mathrm{H})$ dependencies of as-prepared (a); stress-annealed at $\mathrm{T}_{\mathrm{ann}}=300{ }^{\circ} \mathrm{C}$ under $\sigma_{\mathrm{a}}=$ $80 \mathrm{MPa}$ for $10 \mathrm{~min}(\mathbf{b}) ; 30 \mathrm{~min}(\mathbf{c})$, and $\Delta \mathrm{Z} / \mathrm{Z}_{\mathrm{m}}(\mathrm{f})$ dependencies of as-prepared and stress-annealed $\mathrm{Co}_{69.2} \mathrm{Fe}_{4.1} \mathrm{~B}_{11.8} \mathrm{Si}_{13.8} \mathrm{C}_{1.1}$ microwires (d).

Based on these observed dependencies, it can be concluded that stress-annealing is an efficient method for improving the GMI effect in Fe-rich magnetic microwires. Although Co-rich still presents higher GMI ratios, its high cost remains undesirable for some particular applications. Consequently, the advantages of the proposed method allowing GMI-ratio enhancement in Fe-rich microwires is that stress-annealed microwires retain amorphous structure, therefore keeping their excellent plasticity and flexibility, which are typical for amorphous materials.

Presented results are of potential interest for the development of cost-effective magnetic sensors and, more specifically, pT resolution sensors (Electronic Compass for Smart Phones and Biomagnetic Field Sensing, Cardiac Magnetic Activity) [17,49,50] and metamaterials based on the GMI effect [30-32]. 
Developed microwires allow us to achieve extremely high magnetic field sensitivity (up to $10 \% / \mathrm{A} / \mathrm{m}$ ), the highest among non-cryogenic devices; therefore, they are suitable for high-performance magnetic sensors $[12,13,15]$. However, applications of magnetic microwires prepared using the same fabrication method are not restricted to the aforementioned. Recently, other applications of magnetic microwires in medicine, biology, instrumentation, electronic surveillance and the automobile industry, such as magnetic hyperthermia allowing in vitro cancer-cell treatment [51], magnetic shape memory and magnetocaloric effects for magnetic refrigeration [52], and magnetic bistability, allowing magnetic tags development [23], have been proposed.

It is worth noting that the use of nanostructured materials, such as thin films and multilayers, can allow further miniaturization of sensors and devices utilizing the GMI effect [53,54]. Furthermore, thin-film GMI elements are more compatible with integrated electronic devices. However, generally, thin films present a much poorer magnetic softness and GMI ratio. On the other hand, recently, it has been reported that the problem of compatibility of magnetic microwires with integrated electronic circuits was successfully solved [55].

On the other hand, the predicted theoretical maximum GMI ratio is about $3000 \%[56,57]$, which is still a few times superior to the experimentally reported $\Delta \mathrm{Z} / \mathrm{Z}$ values $[12,13,15]$. Therefore, it is expected that technology improvement, as well as the development of effective postprocessing methods, will allow for the achievement of a higher GMI ratio.

\section{Conclusions}

We studied the effect of stress-annealing on the magnetic properties and GMI effect of Feand Co-rich microwires. Stress-annealing allowed remarkable improvement of the GMI effect in both families of magnetic microwires. In Fe-rich microwires, stress-annealing allows for a remarkable magnetic softening. In Co-rich microwires, the highest GMI ratio was observed for stress-annealed Co-rich microwires that presented rectangular hysteresis loops. Stress-annealing induced-magnetic anisotropy was affected by annealing conditions: temperature, time and values of stresses applied during annealing treatments. Stress-annealing allowed for the extension of the frequency range and enhancement of the GMI ratio in both families of studied microwires. Irregular magnetic-field-dependence dependencies of GMI ratio observed in stress-annealed Fe-rich microwires were discussed in terms of the contribution of both inner axially magnetized core and outer shell with transverse magnetic anisotropy.

Author Contributions: Conceptualization, A.Z.; methodology, P.C.-L., A.T. and M.I.; validation, A.Z., J.M.B. and V.Z.; investigation, V.Z., P.C.-L., A.Z. and A.T.; resources, J.G.; data curation, A.Z.; writing-original draft preparation, A.Z. and A.T.; writing—review and editing, A.Z.; visualization, V.Z.; supervision, A.Z.; project administration, A.Z. and J.G.; funding acquisition A.Z. and J.G. All authors have read and agreed to the published version of the manuscript.

Funding: This work was supported by Spanish MCIU, under PGC2018-099530-B-C31 (MCIU/AEI/FEDER, UE), by the Government of the Basque Country under PIBA 2018-44 projects and by the University of Basque Country, under the scheme of "Ayuda a Grupos Consolidados" (Ref.: GIU18/192).

Acknowledgments: The authors thank technical and human support provided by SGIker of UPV/EHU (Medidas Magnéticas Gipuzkoa) and European funding (ERDF and ESF).

Conflicts of Interest: The authors declare no conflicts of interest

\section{References}

1. Beach, R.S.; Berkowitz, A.E. Giant magnetic field dependent impedance of amorphous FeCoSiB wire. Appl. Phys. Lett. 1994, 64, 3652-3654. [CrossRef]

2. Panina, L.V.; Mohri, K. Magneto-impedance effect in amorphous wires. Appl. Phys. Lett. 1994, 65, $1189-1191$. [CrossRef]

3. Harrison, E.P.; Turney, G.L.; Rowe, H.; Gollop, H.; Smith, F.E. The electrical properties of high permeability wires carrying alternating current. Proc. R. Soc. Lond. Ser. Math. Phys. Sci. 1936, 157, 451-479. 
4. Varga, R.; Richter, K.; Zhukov, A.; Larin, V. Domain Wall Propagation in Thin Magnetic Wires. IEEE Trans. Magn. 2008, 44, 3925-3930. [CrossRef]

5. Zhukova, V.; Blanco, J.M.; Rodionova, V.; Ipatov, M.; Zhukov, A. Domain wall propagation in micrometric wires: Limits of single domain wall regime. J. Appl. Phys. 2012, 111, 07E311. [CrossRef]

6. Sixtus, K.J.; Tonks, L. Propagation of Large Barkhausen Discontinuities. II. Phys. Rev. 1932, 42, 419-435. [CrossRef]

7. Goto, T.; Nagano, M.; Wehara, N. Mechanical Properties of Amorphous Fe80P16C3B1 Filament Produced by Glass-Coated Melt Spinning. Trans. Jpn. Inst. Met. 1977, 18, 759-764. [CrossRef]

8. Zhukova, V.; Cobeño, A.F.; Zhukov, A.; de Arellano Lopez, A.R.; Blanco, J.M.; Larin, V.; Gonzalez, J.; López-Pombero, S. Correlation between magnetic and mechanical properties of devitrified glass-coated $\mathrm{Fe}_{71.8} \mathrm{Cu}_{1} \mathrm{Nb}_{3.1} \mathrm{Si}_{15} \mathrm{~B}_{9.1}$ microwires. J. Magn. Magn. Mater. 2002, 249, 79-84. [CrossRef]

9. Ogasawara, I.; Ueno, S. Preparation and properties of amorphous wires. IEEE Trans. Magn. 1995, 31, 1219-1223. [CrossRef]

10. Rudkowski, P.; Rudkowska, G.; Strom-Olsen, J.O. The fabrication of fine metallic fibers by continuous melt-extraction and their magnetic and mechanical properties. Mater. Sci. Eng. A 1991, 133, $158-161$. [CrossRef]

11. Chiriac, H.; Lupu, N.; Stoian, G.; Ababei, G.; Corodeanu, S.; Óvári, T.-A. Ultrathin Nanocrystalline Magnetic Wires. Crystals 2017, 7, 48. [CrossRef]

12. Zhukov, A.; Zhukova, V.; Blanco, J.M.; Gonzalez, J. Recent research on magnetic properties of glass-coated microwires. J. Magn. Magn. Mater. 2005, 294, 182-192. [CrossRef]

13. Pirota, K.R.; Kraus, L.; Chiriac, H.; Knobel, M. Magnetic properties and giant magnetoimpedance in a CoFeSiB glass-covered microwire. J. Magn. Magn. Mater. 2000, 221, L243-L247. [CrossRef]

14. Klein, P.; Varga, R.; Badini-Confalonieri, G.A.; Vazquez, M. Study of domain structure and magnetization reversal after thermal treatments in $\mathrm{Fe}_{40} \mathrm{Co}_{38} \mathrm{Mo}_{4} \mathrm{~B}_{18}$ microwires. J. Magn. Magn. Mater. 2011, 323, 3265-3270. [CrossRef]

15. Corte-León, P.; Zhukova, V.; Ipatov, M.; Blanco, J.M.; Gonzalez, J.; Zhukov, A. Engineering of magnetic properties of Co-rich microwires by joule heating. Intermetallics 2019, 105, 92-98. [CrossRef]

16. Mohri, K.; Uchiyama, T.; Shen, L.P.; Cai, C.M.; Panina, L.V. Amorphous wire and CMOS IC-based sensitive micro-magnetic sensors (MI sensor and SI sensor) for intelligent measurements and controls. J. Magn. Magn. Mater. 2002, 249, 351-356. [CrossRef]

17. Uchiyama, T.; Mohri, K.; Nakayama, S. Measurement of Spontaneous Oscillatory Magnetic Field of Guinea-Pig Smooth Muscle Preparation Using Pico-Tesla Resolution Amorphous Wire Magneto-Impedance Sensor. IEEE Trans. Magn. 2011, 47, 3070-3073. [CrossRef]

18. Honkura, Y. Development of amorphous wire type MI sensors for automobile use. J. Magn. Magn. Mater. 2002, 249, 375-381. [CrossRef]

19. Zhukova, V.; Corte-Leon, P.; Ipatov, M.; Blanco, J.M.; Gonzalez-Legarreta, L.; Zhukov, A. Development of Magnetic Microwires for Magnetic Sensor Applications. Sensors 2019, 19, 4767. [CrossRef]

20. Zhukov, A.; Vázquez, M.; García-Beneytez, J.M. Magnetoelastic sensor for signature identification based on mechanomagnetic effect in amorphous wires. J. Phys. IV 1998, 8, Pr2-763-Pr2-766. [CrossRef]

21. Zhukov, A.; Cobeño, A.F.; Gonzalez, J.; Blanco, J.M.; Aragoneses, P.; Dominguez, L. Magnetoelastic sensor of liquid level based on magnetoelastic properties of Co-rich microwires. Sens. Actuators Phys. 2000, 81, 129-133. [CrossRef]

22. Cobeño, A.F.; Zhukov, A.; Blanco, J.M.; Larin, V.; Gonzalez, J. Magnetoelastic sensor based on GMI of amorphous microwire. Sens. Actuators Phys. 2001, 91, 95-98. [CrossRef]

23. Makhnovskiy, D.; Fry, N.; Zhukov, A. On different tag reader architectures for bistable microwires. Sens. Actuators Phys. 2011, 166, 133-140. [CrossRef]

24. Dolabdjian, C.; Ménard, D. Giant Magneto-Impedance (GMI) Magnetometers. In High Sensitivity Magnetometers; Smart Sensors, Measurement and Instrumentation; Grosz, A., Haji-Sheikh, M.J., Mukhopadhyay, S.C., Eds.; Springer: Cham, Switzerland, 2017; pp. 103-126. ISBN 978-3-319-34070-8.

25. Dufay, B.; Saez, S.; Dolabdjian, C.; Yelon, A.; Menard, D. Development of a High Sensitivity Giant Magneto-Impedance Magnetometer: Comparison with a commercial flux-Gate. IEEE Trans. Magn. 2013, 49, 85-88. [CrossRef] 
26. Ripka, P.; Vértesy, G. Sensors based on soft magnetic materials Panel discussion. J. Magn. Magn. Mater. 2000, 215-216, 795-799. [CrossRef]

27. Praslicka, D.; Blazek, J.; Smelko, M.; Hudak, J.; Cverha, A.; Mikita, I.; Varga, R.; Zhukov, A. Possibilities of measuring stress and health monitoring in materials using contact-less sensor based on magnetic microwires. IEEE Trans. Magn. 2013, 49, 128-131. [CrossRef]

28. Hauser, M.; Kraus, L.; Ripka, P. Giant magnetoimpedance sensors. IEEE Instrum. Meas. Mag. 2001, 4, $28-32$. [CrossRef]

29. La Spada, L.; Vegni, L. Electromagnetic Nanoparticles for sensing and medical diagnostic applications. Materials 2018, 11, 603. [CrossRef]

30. Panina, L.V.; Ipatov, M.; Zhukova, V.; Zhukov, A.; Gonzalez, J. Microwave metamaterials with ferromagnetic microwires. Appl. Phys. A Mater. Sci. Process. 2011, 103, 653-657. [CrossRef]

31. Qin, F.X.; Pankratov, N.; Peng, H.X.; Phan, M.H.; Panina, L.V.; Ipatov, M.; Zhukova, V.; Zhukov, A.; Gonzalez, J. Novel magnetic microwires-embedded composites for structural health monitoring applications. J. Appl. Phys. 2010, 107, 09A314. [CrossRef]

32. Allue, A.; Corte-León, P.; Gondra, K.; Zhukova, V.; Ipatov, M.; Blanco, J.M.; Gonzalez, J.; Churyukanova, M.; Taskaev, S.; Zhukov, A. Smart composites with embedded magnetic microwire inclusions allowing non-contact stresses and temperature monitoring. Compos. Part A 2019, 120, 12-20. [CrossRef]

33. Blanco, J.M.; Zhukova, V.; Ipatov, M.; Zhukov, A. Magnetic Properties and Domain Wall Propagation in Micrometric Amorphous Microwires. Sens. Lett. 2013, 11, 187-190. [CrossRef]

34. Ménard, D.; Britel, M.; Ciureanu, P.; Yelon, A. Giant magnetoimpedance in a cylindrical magnetic conductor. J. Appl. Phys. 1998, 84, 2805-2814. [CrossRef]

35. Phan, M.-H.; Peng, H.-X. Giant magnetoimpedance materials: Fundamentals and applications. Prog. Mater. Sci. 2008, 53, 323-420. [CrossRef]

36. Talaat, A.; Zhukova, V.; Ipatov, M.; del Val, J.J.; Gonzalez-Legarreta, L.; Hernando, B.; Blanco, J.M.; Zhukov, A. Effect of nanocrystallization on giant magnetoimpedance effect of Fe-based microwires. Intermetallics 2014, 51, 59-63. [CrossRef]

37. Talaat, A.; Zhukova, V.; Ipatov, M.; del Val, J.J.; Blanco, J.M.; Gonzalez-Legarreta, L.; Hernando, B.; Churyukanova, M.; Zhukov, A. Engineering of magnetic softness and mMagnetoimpedance in Fe-Rich microwires by nanocrystallization. JOM 2016, 68, 1563-1571. [CrossRef]

38. Zhukov, A.; Ipatov, M.; Corte-León, P.; Legarreta, -L.G.; Churyukanova, M.; Blanco, J.M.; Gonzalez, J.; Taskaev, S.; Hernando, B.; Zhukova, V. Giant magnetoimpedance in rapidly quenched materials. J. Alloys Compd. 2020, 814, 152225. [CrossRef]

39. Zhukova, V.; Blanco, J.M.; Ipatov, M.; Churyukanova, M.; Taskaev, S.; Zhukov, A. Tailoring of magnetoimpedance effect and magnetic softness of Fe-rich glass-coated microwires by stress-annealing. Sci. Rep. 2018, 8, 1-14. [CrossRef]

40. Talaat, A.; Zhukova, V.; Ipatov, M.; Blanco, J.M.; Gonzalez, J.; Zhukov, A. Impact of stress annealing on the magnetization process of amorphous and nanocrystalline Co-based microwires. Materials 2019, 12, 2644. [CrossRef]

41. Zhukov, A.; Churyukanova, M.; Kaloshkin, S.; Sudarchikova, V.; Gudoshnikov, S.; Ipatov, M.; Talaat, A.; Blanco, J.M.; Zhukova, V. Magnetostriction of Co-Fe-based amorphous soft magnetic microwires. J. Electron. Mater. 2016, 45, 226-234. [CrossRef]

42. Zhukov, A.; Talaat, A.; Ipatov, M.; Zhukova, V. Tailoring the high-frequency giant magnetoimpedance effect of amorphous Co-rich microwires. IEEE Magn. Lett. 2015, 6, 1-4. [CrossRef]

43. Zhukov, A.; Talaat, A.; Ipatov, M.; Blanco, J.M.; Zhukova, V. Tailoring of magnetic properties and GMI effect of Co-rich amorphous microwires by heat treatment. J. Alloys Compound. 2014, 615, 610-615. [CrossRef]

44. Zhukov, A.; Ipatov, M.; Corte-León, P.; Gonzalez-Legarreta, L.; Blanco, J.M.; Zhukova, V. Soft Magnetic Microwires for Sensor Applications. J. Magn. Magn. Mater. 2020. [CrossRef]

45. Usov, N.A.; Antonov, A.S.; Lagar'kov, A.N. Theory of giant magneto-impedance effect in amorphous wires with different types of magnetic anisotropy. J. Magn. Magn. Mater. 1998, 185, 159-173. [CrossRef]

46. Mohri, K.; Humphrey, F.B.; Kawashima, K.; Kimura, K.; Mizutani, M. Large Barkhausen and Matteucci effects in FeCoSiB, FeCrSiB, and FeNiSiB amorphous wires. IEEE Trans. Magn. 1990, 26, 1789-1791. [CrossRef]

47. Vazquez, M.; Chen, D.-X. The magnetization reversal process in amorphous wires. IEEE Trans. Magn. 1995, 31, 1229-1238. [CrossRef] 
48. Zhukova, V.; Blanco, J.M.; Chizhik, A.; Ipatov, M.; Zhukov, A. AC-current-induced magnetization switching in amorphous microwires. Front. Phys. 2018, 13, 137501. [CrossRef]

49. Mohri, K.; Uchiyama, T.; Panina, L.V.; Yamamoto, M.; Bushida, K. Recent Advances of Amorphous Wire CMOS IC Magneto-Impedance Sensors: Innovative High-Performance Micromagnetic Sensor Chip. J. Sens. 2015, 718069. [CrossRef]

50. Nakayama, S.H.; Sawamura, K.; Mohri, K.; Uchiyama, T. Pulse-driven magnetoimpedance sensor detection of cardiac magnetic activity. PLoS ONE 2011, 6, e25834. [CrossRef]

51. Mitxelena-Iribarren, O.; Campisi, J.; Martínez de Apellániz, I.; Lizarbe-Sancha, S.; Arana, S.; Zhukova, V.; Mujika, M.; Zhukov, A. Glass-coated ferromagnetic microwire-induced magnetic hyperthermia for in vitro cancer cell treatment. Mater. Sci. Eng. C 2020, 106, 110261. [CrossRef]

52. Zhukov, A.; Rodionova, V.; Ilyn, M.; Aliev, A.M.; Varga, R.; Michalik, S.; Aronin, A.; Abrosimova, G.; Kiselev, A.; Ipatov, M.; et al. Magnetic properties and magnetocaloric effect in Heusler-type glass-coated NiMnGa microwires. J. Alloys Compd. 2013, 575, 73-79. [CrossRef]

53. Kikuchi, H.; Sumida, C. Analysis of asymmetric property with DC bias current on thin-film magnetoimpedance element. AIP Adv. 2018, 8, 056618. [CrossRef]

54. Karnaushenko, D.; Karnaushenko, D.D.; Makarov, D.; Baunack, S.; Schäfer, R.; Schmidt, O.G. Self-Assembled On-Chip-Integrated Giant Magneto-Impedance Sensorics. Adv. Mater. 2015, 27, 6582-6589. [CrossRef] [PubMed]

55. Honkura, Y.; Honkura, S. The Development of ASIC Type GSR Sensor Driven by GHz Pulse Current. In Proceedings of the Ninth International Conference on Sensor Device Technologies and Applications SENSORDEVICES 2018, Venice, Italy, 16-20 September 2018; ISBN 978-1-61208-660-6.

56. Kraus, L. Theory of giant magneto-impedance in the planar conductor with uniaxial magnetic anisotropy. J. Magn. Magn. Mater. 1999, 195, 764-778. [CrossRef]

57. Zhukov, A.; Ipatov, M.; Churyukanova, M.; Talaat, A.; Blanco, J.M.; Zhukova, V. Trends in optimization of giant magnetoimpedance effect in amorphous and nanocrystalline materials. J. Alloys Compd. 2017, 727, 887-901. [CrossRef]

(C) 2020 by the authors. Licensee MDPI, Basel, Switzerland. This article is an open access article distributed under the terms and conditions of the Creative Commons Attribution (CC BY) license (http://creativecommons.org/licenses/by/4.0/). 